International Journal of Child, Youth and Family Studies (2018) 9(1): 38-60

DOI: $10.18357 /$ ijcyfs92201818212

\title{
ACKNOWLEDGING THE COMPLEXITY OF PROCESSES LEADING TO FOSTER CARE BREAKDOWN
}

\author{
Clara Bombach, Thomas Gabriel, and Renate Stohler
}

\begin{abstract}
Family-based solutions for children in care are the preferred option in European countries on the grounds of both cost and quality. Yet, too often, foster care placements intended to be long term are terminated unexpectedly early. Few studies have identified factors leading to unexpected breakdown and fewer still have translated such findings into practical guidance for professionals. This article outlines: (a) the ambiguity and contradictions in the use of terminology (e.g., instability, breakdown, disruption) in several international studies; (b) the adoption of a one-sided, file-based, systemic perspective in recent studies of foster care instability, breakdown, and disruption; and (c) empirical data collected from interviews with foster children. Foster care breakdown is shown to be a process that takes place on several levels. In addition to the actual breakdown event, the situation of the child before the placement, the situation during the placement, the emergence and development of the crisis and the consequences of the breakdown for all those involved are all part of the process. It is only in retrospect that the ending of a foster care process is perceived as a breakdown. Assessments of whether it was planned or unplanned, expected or unexpected, and desirable or undesirable are meaningful only from an individual perspective. Such a perspective must be clearly identified: different people experience and remember the same breakdown in different ways, and its significance for their personal biographies may vary.
\end{abstract}

Keywords: foster care, breakdown, placement change, perspective of foster children

Clara Bombach MA (the corresponding author) is a research associate at Zurich University of Applied Sciences, School of Social Work, Institute of Childhood, Youth and Family, Pfingstweidstrasse 96, 8037 Zurich, Switzerland. Email: clara.bombach@ zhaw.ch

Thomas Gabriel PhD is the head of the Institute of Childhood, Youth and Family at Zurich University of Applied Sciences, School of Social Work, Pfingstweidstrasse 96, 8037 Zurich, Switzerland. Email: thomas.gabriel@zhaw.ch

Renate Stohler lic.phil is a lecturer and project leader at Zurich University of Applied Sciences, School of Social Work, Institute of Childhood, Youth and Family, Pfingstweidstrasse 96, 8037 Zurich, Switzerland. Email: renate.stohler@zhaw.ch 
Family-based solutions for children in care are the preferred option in European countries on the grounds of both cost and quality (Delap \& Melville Fulford, 2011). Yet, too often, foster care placements intended to be long term are terminated unexpectedly early (Kindler, Helmig, Meysen, \& Jurczyk, 2011; Wilson, Sinclair, \& Gibbs, 2000). Few studies have identified factors leading to unexpected breakdown and fewer still have translated such findings into practical guidance for professionals (Rock, Michelson, Thomson, \& Day, 2013; Semanchin Jones \& Wells, 2008). Studies of unexpected foster care termination or breakdown have adopted a range of definitions of "breakdown", which has hindered comparison. While Oosterman, Schuengel, Slot, Bullens, and Doreleijers's (2007) review of literature on "placement breakdown" was "based on the assumption that multiple moves between foster homes and group homes are universally seen as undesirable", Christiansen, Havik, and Anderssen (2010, p. 915) preferred a definition of breakdown as something that arises "when a child moves from a placement intended to persist except for moves from an acceptable arrangement to a better one." Differences also exist in relation to policy contexts, legislation, and philosophies of care that give rise to variations in the role and remit of foster care. These differences may impact the conclusions of studies of foster care breakdown, which are usually confined to a single country and thus limit the extent of crossnational knowledge transfer. There is little international consensus regarding the concepts and tools to be used in the measurement and assessment of foster care breakdown.

An international team comprising researchers from the ZHAW ${ }^{1}$ School of Social Work in Switzerland, the University of Siegen in Germany, and the University of London in England has been carrying out research on a project entitled "Foster Care Breakdown" since 2014. The aim of the study is to evaluate the reasons why foster care placements in England, Germany, and Switzerland break down. It sets out to identify the factors that play a role in the breakdown of foster care placements and examines the unfolding of the processes that lead to such breakdowns. ${ }^{2}$ To fulfil these objectives, the project team conducted interviews with foster children and parents and analyzed files relating to foster care placements.

The title of the project prompted different reactions among foster children, foster parents, professionals from child and youth welfare services, and researchers. Far from being selfexplanatory, it proved to require considerable clarification. The researchers in all three countries observed that when seeking to approach interviewees and specialist services with a view to accessing files for analysis, the project title frequently provoked irritation and had a deterrent effect. For example, requests for access to files for analysis were denied with the explanation that

\footnotetext{
${ }^{1}$ Zurich University of Applied Sciences, School of Social Work, Institute of Childhood, Youth and Family: www.zhaw.ch/socialwork.

${ }^{2}$ More detailed information about the ongoing project can be found at: https://www.zhaw.ch/en/socialwork/research/kindheit-jugend-und-familie/kinder-und-jugendhilfe/foster-careplacement-breakdown/.
} 
breakdowns were extremely rare and only arose in highly complex individual cases. This prompted the project team to undertake a critical evaluation of the research tradition, terminology, and data pool in the context of the current research on the topic. An effort was also made to clarify the use of terminology within the project, with the aim of developing a definition of foster care breakdown that would incorporate the experience of foster families and foster children and would be suitable for use in the analysis of files and for the exchange of information and the sharing of experiences between professionals from foster care services. It was also seen as important to decode the connotations conveyed in the project title and to discuss the participating researchers' own approach to the designation of foster care breakdown.

We begin by exploring the current status of the research on foster care breakdown and its designation, and by identifying the dimensions conveyed by the majority of the associated definitions and terminology. We then show, based on 13 interviews carried out with foster children who had experienced the breakdown of a foster care placement in Switzerland, that the dimension of experience should be regarded as a key factor in the development of such definitions.

\section{Foster Care Breakdown in Switzerland}

According to an estimate by Pflegekinder-Aktion Schweiz. [Foster Child Action Switzerland] and Integras [Swiss National Association for Social Pedagogy and Special Needs Education], between 22,000 and 30,000 children and young people in Switzerland do not currently live with their parents (Keller, 2012). However, national statistics for foster placements are not recorded: no national data are available on the "total childcare population, care leavers or children in need. At the national level there are also no data available on placement types, lengths of stay in care or on the age profile of looked after children" (Gabriel \& Stohler, 2008, p. 197). Little research has been carried out on children in foster care, despite the fact that the need for such research was referred to in the mid-1970s (Kuntsche \& Nett, 2002) and highlighted when National Councillor Jacqueline Fehr published her parliamentary postulate on the Swiss foster care system in 2002, in which she claimed that there was a need for more research and data (Zatti, 2005). Little is known about the rate of foster care breakdown in Switzerland or about the conditions necessary to reduce the unexpected termination of long-term placements. Similarly, not much is known about foster care stability in Switzerland or about the promotion of placement stability by social services. Figures that provide some points of reference are currently available from two cantons. First, the surveys carried out by the Bildungsdirektion des Kantons Zürich, Amt für Jugend und Berufsberatung [Office for Youth and Career Guidance of the canton of Zurich Department of Education] reveal that, in the early 2000s, the breakdown of foster care "due to conflicts between the family and foster child or birth family and at the request of the parent or foster child" (Bildungsdirektion Kanton Zürich. Amt für Jugend und Berufsberatung, 2014, p. 4) was as follows: $34 \%$ of foster care placements were terminated in 2002, 31\% in 2003, and 25\% in 2005 . The report states that, "In view of the fact that the termination of a foster care placement generally has a severe impact on the affected child, the average figure of $30 \%$ breakdowns should be assessed as high" (p. 4). Also, according to assessments conducted by professionals responsible for foster 
International Journal of Child, Youth and Family Studies (2018) 9(1): 38-60

care placements in the canton of Bern (Kantonales Jugendamt, 2016), about a quarter of departures from placements in 2016 were described as "unplanned", and "this can mean the termination of the care by either the service recipient or the service provider" (p. 14). It is also stated in another part of the report that almost 90 percent of all departures from foster care placements can be assessed as planned (Kantonales Jugendamt, 2016, p. 21). The obvious contradiction between these statements is not explained.

\section{Definitions and Statistics: Ambiguity and Inconsistencies}

The challenges presented by the conceptualization of foster care breakdown are due in part to the inconsistent and inaccurate use of terminology in both theory and practice (James, 2004; Newton, Litrownik, \& Landsverk, 2000). Various attempts have been made to determine how often breakdowns arise among children and young people in foster care placements: reviews of factors relating to foster care breakdown, such as those by Oosterman et al. (2007), Christiansen et al. (2010), and Rock et al. (2013), have found that there is a variation of between $20 \%$ and $50 \%$ in the rate of breakdown or placement change across different studies and countries. This considerable variation in the data can partly be explained by the lack of consistency in the definitions of foster care breakdown employed; moreover, the rates of breakdown are also influenced by differences in systems and practices. Whereas long-term placements are avoided where possible in the United States and Great Britain (the aim being to have foster children adopted as quickly as possible), it is not uncommon for foster children in Switzerland to spend their entire childhood and youth with one or more foster families (Festinger, 2014).

Despite - or because of - these difficulties in the conceptualization of foster care breakdown, we will discuss the attempts that have been made at defining the concepts encountered in the international research literature and identify the defining characteristics on which they are based.

\section{Placement Change}

In the English-language literature, all forms of change from one professionally supervised residential or semiresidential care situation to a different one tend to be subsumed under the terms "placement change" or "placement move". In the area of child and youth welfare, these changes include, for example, the moving of a child or young person from a foster family to a residential facility, or the interruption of residential care by a temporary time-out placement. Andersen (2014) also includes the return of the child or young person to the family of origin in her definition of placement change. Pecora (2010) sees all changes in place of residence as a placement change. While he defines change as spatial (place of residence), his definition also incorporates the changes that arise in the child's or young person's relationships with adults in a shared household as a result of such moves. 
International Journal of Child, Youth and Family Studies (2018) 9(1): 38-60

\section{Unplanned Placement Change}

Placement changes can be planned in advance or be decided on and implemented in the course of a foster care placement. In addition to these planned forms of change, the term "placement change" also covers moves that can be described as unplanned or unexpected. The terms "premature" (Rostill-Brookes, Larkin, Toms, \& Churchman, 2011; Vanderfaeillie, Van Holen, \& Coussens, 2008), "unintended" (Backe-Hansen, 2010) and "unplanned" (Proch \& Traber, 1985) are also used in the international literature. The terms used to designate these unplanned and unexpected forms of placement change are ambiguous and often used synonymously, and precise definitions are not usually given. For example, Rostill-Brookes et al. (2011) use the terms "foster placement breakdown", "premature end of placement", "placement disruption", and "moving placement" in the same article. Ekins (2009) uses the term "failure" in her exploration of the topic, while Vanderfaeillie et al. (2008) adopt the more neutral "termination of placement".

Gilbertson \& Barber (2003) present an overview of studies that demonstrate the negative long-term consequences of the breakdown of placements on foster children, such as unemployment, low educational attainment, and homelessness. It is generally accepted that unplanned placement changes have negative consequences for the affected children and young people and, correspondingly, that continuity and stability in foster care is the desired objective (Brown, Bednar, \& Sigvaldason, 2007). The arguments used are based mainly on attachment theory (Barber \& Delfabbro, 2003; Ekins, 2009; Newton et al., 2000).

\section{Breakdown}

Berridge \& Cleaver (1987) coined the term "breakdown" for unplanned and unexpected forms of placement change and it prevails to the present day in the English-language literature discourse originating from both Europe (Andersen, 2014 [Denmark]; Backe-Hansen, 2010 [Norway]; Egelund \& Vitus, 2009 [Denmark]; Kalland \& Sinkkonen, 2001 [Finland]; Khoo \& Skoog, 2014 [Sweden]; López López, del Valle, Montserrat, \& Bravo, 2011 [Spain]; Sallnäs, Vinnerljung, \& Kyhle Westermark, 2004 [Sweden]; Vanderfaeillie et al., 2008 [Belgium]; Vinnerljung, Sallnäs, \& Berlin, 2014 [Sweden]) and Canada (Brown et al., 2007; Gilbertson \& Barber, 2003; Palmer, 1990). Van Santen (2013) used the English term "breakdown" in the German-language context and it was translated as Scheitern [failure] by Gehres (2007) and Heinemann (1994), as ungeplante Beendigungen [unplanned terminations] by Hédevári-Heller (2000) and as Abbruch [termination or breaking off] in a report published in Switzerland (Bericht und Antrag des Regierungsrates, 2007).

Although "breakdown" is used to describe unplanned placement changes to the present day, its negative connotations, which are expressed particularly clearly in the German term Scheitern, are often criticised. "Breakdown" is also disliked because it is at odds with the implications and objectives of the placement - the creation of the maximum possible stability and continuity. The term implies the cessation of all links between the child and foster parents or 
International Journal of Child, Youth and Family Studies (2018) 9(1): 38-60

caregivers; that is, a clear end to a placement situation. However, studies show that foster children may continue to have contact with the former care setting after the breakdown of a placement (Backe-Hansen, 2010; Unrau, 2007; Unrau, Seita, \& Putney, 2008).

\section{Positive Reversal and Concealment}

The term "breakdown" is not used in the widely-cited U.S. studies of the past 20 years. Unplanned placement changes are referred to instead using the term "disruption" (Hyde \& Kammerer, 2009; James, 2004; Newton et al., 2000; Rubin, O’Reilly, Luan, \& Localio, 2007; Semanchin Jones \& Wells, 2008; Unrau et al., 2008). Unlike breakdown, this term does not imply a definitive end to a placement and evokes instead the impression of interruption that could involve short-term instability but could possibly also serve the interests of long-term stability with regard to the development of the child and the continuity of their relationships with adults. For this reason, the expression "improving stability", which positions interruptions or breakdowns in a broader context, is becoming more common; it is also used in the Australian literature (Barber \& Delfabbro, 2013; Gilbertson \& Barber, 2003). This means that these events are no longer limited in temporal or spatial terms or in terms of the child's or young person's relationships with adults and are conceived instead as capable of being worked on and, possibly, as predictable from the perspective of professional practice. In practical terms, based on this logic the professionals supporting the care relationship have the capacity to act: they can respond, offer support, and prevent crises. It is becoming clear that better planning is required for foster placements: objectives must be well defined and their implementations monitored.

This leads to the question of whose perspective the breakdowns are described from. It may be assumed that the terminology was coined by those who see themselves as being in a position to avoid breakdowns, the actors who intervene in, change, and provide professional support for foster care relationships.

What should also be examined here is the extent to which, and within what timeframe, it is possible to plan or predict the development of complex life circumstances that change and reconstitute themselves. Reimer (2015) demonstrates this complexity clearly. Referring to Geertz (1987), she shows that culture is constantly being newly interpreted and defined, that it is never objective, and that it is produced through everyday human action (p. 66). This "collectively developed system of meanings" (p. 66) cannot necessarily be accessed from outside:

When a child comes to a new family, they must ... become familiar with and learn to understand the family's culture. ... The child must learn to interpret and understand the family's symbols while simultaneously overcoming the at least partial loss of their own relationships, habits and familiar environment. (Reimer, 2015, p. 68)

The aim of child welfare practice is to facilitate the establishment of stable, reliable, and long-term relationships between children and young people and the adults in their lives; instability 
and interruptions are considered undesirable, destructive, and often negative for everyone involved. This view is supported by attachment theory, which holds that stable and long-term relationships are more positive for the development of the child (Nienstedt \& Westermann, 1999; Oosterman et al., 2007). Also, studies have shown stability has a positive impact on the long-term consequences of foster and residential care placements (Jackson \& Cameron, 2012; Stein, 2006; Stein, 2012; Ward, 2009).

As noted in describing the "Foster Care Breakdown" project, the authorities initially refused to make files available for analysis or to inform foster parents and children about the possibility of participating in interviews about foster care breakdown. One of the conclusions the researchers drew from this was that those authorities' negative view of foster care breakdown is at odds with child welfare practice efforts to provide support for foster care placements so that the aim of ensuring the well-being of the child can be fulfilled. The authorities also felt that the majority of placement changes were foreseeable and could not therefore be described as breakdowns. However, following discussion about what kind of events can be understood as breakdowns, it was not uncommon for us to be provided with numerous files for qualitative analysis and to be put in touch with (former) foster children and parents who had experienced foster care breakdown.

Thus positive reversal, the avoidance by authorities of the terms "breakdown" and "instability", side-steps the negative connotations associated with the traditional use of these terms. This avoidance strategy could also be interpreted critically as concealment. The attempt to restrict the use of the term "breakdown" to the most serious cases and to introduce alternatives based more on the neutral, general category of "placement change" can be found in the use of terminology in both the United States and the United Kingdom. ${ }^{3}$ The use of such terms as an alternative for "breakdown" is an attempt to move away from the negative connotations of failure, disruption, and collapse. However, as demonstrated by the unclear definitions and synonymous use of these terms, this aim is not pursued in a sustained and consistent way. Moreover, terminology use from the United States or the United Kingdom has virtually no impact on the way breakdown is designated in English-language publications from non-English-speaking countries. For these reasons, this article still uses the term "foster care breakdown".

\section{System Logic Channels Attention to the Child's Behaviour}

The neutral terms that are frequently used in quantitative, file-based studies can be understood against the background of a particular system logic: the avoidance of breakdowns. In these studies, factors leading to the breakdown are identified on different levels of the process

\footnotetext{
${ }^{3}$ To this end, Proch \& Traber (in James, 2004) introduced the composite term "unplanned move" as far back as 1985. Similar to the above-mentioned general category of "placement change", the terms "change" and "move" are used synonymously with "disruption" in the U.S. literature. The same applies to more recent literature from the United Kingdom which no longer uses the term "breakdown", despite the fact that it was coined there by Berridge and Cleaver (1987).
} 
(before, during, and after placement), but are rarely considered in context or are merely presented uncritically from a file-based perspective. To be consistent with the system logic, factors such as the behaviour of the child or young person must be clearly designated as the cause of the breakdown in order to enable the legitimization of eventual reactions like sanctions and interventions. From the perspective of the system, the visibility of negative behaviour generates key moments of evaluation and categorization and also legitimizes its work. The foster care service in Switzerland has developed a comprehensive catalogue of authorized targeted responses to the behavioural problems of children, such as "time-outs" - temporary moves to different settings (Bombach, Stohler, \& Wydler, 2015).

In the quantitative research on foster care breakdowns, the definitions of the terms predominantly used relate specifically to the point in time at which the foster care situation ends. The factors cited as explanations for the breakdown are very often described one-sidedly and are often attributed to the foster child. The attention is mainly focused on the negative consequences of the breakdown for the child. According to various, mainly quantitative studies, frequently cited reasons for breakdown that are attributed to the foster child include: behavioural and attachment problems on the part of the child (James, 2004; van Santen, 2013; Vanderfaeillie et al., 2008), divided affiliations and loyalties (Blandow, 2004; van Santen, 2013), and school problems (Ekins, 2009; van Santen, 2013). Reasons for breakdown attributed to the foster parents include: subjecting the foster child to physical or sexual abuse (James, 2004; Price et al., 2008; Vanderfaeillie et al., 2008), being unable to cope (Andersen, 2014; Gehres, 2007), demanding an exclusive relationship (Gehres, 2007), suffering too much stress from the behaviour of the foster child (James, 2004), being affected by critical life events (Ekins, 2009; James, 2004), and not receiving enough support from the social network (Ekins, 2009; Price et al., 2008; van Santen, 2013). Factors relating to the system are relatively rarely identified as a cause of breakdown, and little attention is paid to the interaction between the different actors involved in the process (birth family, foster family, foster child, foster siblings, representatives of the authorities, social workers, etc.). References are made to emerging difficulties and "rivalries between family systems" (van Santen, 2013), unclear arrangements and poorly implemented support services on the part of the child welfare system (Ekins, 2009; Gehres, 2007; Price et al., 2008), and the insufficient availability of information about the foster child (Kalland \& Sinkkonen, 2001).

Another central factor that has received little or no attention up until now emerged from the file analyses and the interviews with foster children and parents carried out as part of the "Foster Care Breakdown" project: the foster care service system itself can cause breakdowns and trigger breakdown processes. This can arise when the regulations relating to third-party placements are changed; for example, when a new permit is required that the foster family is unable to provide. In one such case encountered by the project, a foster family would have had to register as a Kleinheim [small residential care unit] to enable a foster child to remain with them in the long term. The family refused to do this for various reasons, resulting in a change of placement for the foster child. 
International Journal of Child, Youth and Family Studies (2018) 9(1): 38-60

\section{A One-Sided View of Negative Problem Constellations}

The majority of studies on the topic of foster care breakdown adopt a predominantly negative perspective and aim to reduce problem constellations to factors that constitute reasons for foster care breakdowns, often from an uncritical and one-sided (file-based) point of view. The perspectives of the affected children and young people have rarely been taken into account and have played only a marginal role in shaping the discourse. Thus the research literature rarely contains references to the complex ambivalent effects of foster relationship breakdowns, which could possibly also be experienced in a positive way; they have "the potential to be both helpful and harmful to children in their journey through care" (Unrau, 2007, p. 132). Accordingly, breakdowns should be understood as "a solution that always both limits and creates options" (Gehres, 2007, p. 76).

According to Unrau (2007), one reason for this situation is that most international research on this topic relies on a one-sided view that is focused on a particular point in time and is based on the analysis of files, and quantitative assessment of factors relating to unplanned breakdowns. Thus, quantitative studies based on the analysis of files specify the "behavioural problems" of children and young people as the main reason for foster care breakdown (see, for example, Barber \& Delfabbro, 2003; Pecora et al., 2003). This methodological error leads to attributing blame for the breakdown to the children and young people themselves, thereby concealing the systemic factors at work (Wulczyn, 2010).

\section{One-sided Accounts Insufficient}

The analysis of files carried out as part of the "Foster Care Breakdown" study often yielded contradictory results: when the social workers involved in a case were asked to name the reason for the breakdown of a foster care placement, they frequently referred to the situation that prevailed at the end of the process; that is, the child's departure from the foster family. In the course of the qualitative analysis of the files, the research team often identified other, sometimes more complex, situations that came to a head in the event referred to by the social worker. Without those preceding experiences, the event might not have resulted in the termination of the placement. Van Santen (2013) also refers to this important distinction:

The initiative in instigating the breakdown of a placement cannot be equated with the cause of the breakdown. ... The decision may be taken at the end of a chain of (co-determined) decisions, any of which may themselves be shot through with ambivalence. (p. 8)

The role, remit, and limited insight of case reporters, whose opinions, observations, decisions, and interview notes are recorded in the files, have received far too little attention in the discussion of such outcomes. Studies have provided little critical reflection on the dependencies, interests, roles, and remits of the supervising professionals (see, for example, López López et al., 2011; Pecora et al., 2003; Pecora et al., 2005). The quantitative research tradition has consistently 
International Journal of Child, Youth and Family Studies (2018) 9(1): 38-60

ignored the demand arising from qualitative studies (e.g., Unrau \& Day, 2010) that the actors directly affected by foster care breakdown must be called on to describe their own experiences, ensuring that dimensions with a subjective significance are also recorded. Foster children are the focus of all measures but they are all too rarely the focus of the research.

This observation prompts the question as to which facts are considered valuable in the research. This is mainly determined by the actors that provide and control research funding. Is there any willingness to adopt alternative approaches and record the perspectives of those directly affected by measures, whose individual experiences should be the focus of the research studies? Or is it taken as a given that funding will only be provided for research designs that record onesided perspectives but promise to do so for a large number of cases and thereby frequently reinforce the existing system logic?

\section{Foster Children's Experiences of Foster Care Breakdown}

The fact that relatively little comparative research exists on the topic of foster care breakdown reflects the complexity of such breakdowns, which are, from the perspective of foster children and parents, highly variable processes. Breakdown "is not considered the 'antithesis of stability' or a moment when everything falls apart." (Backe-Hansen, 2010, p. 240). Egelund and Vitus (2009) concluded: "We cannot assume that breakdown of care is always a negative result of placement. While this can be the case, more often placement breakdown is a process that takes place over time characterised by multiple contributing factors." (p. 46). To be able to incorporate this complexity into the research project, interviews were also conducted with foster children who had experienced foster care breakdown. The aim was to record different experiences and ascertain individual assessments of the situations under examination.

\section{Field Access and Sample}

Through different channels, the foster children were informed about the research project and the possibility that they could report on their experiences of foster care breakdown: networks were activated, requests were submitted to offices that support and supervise foster children, and calls for interviews were disseminated through the distribution of flyers in various locations which were then passed on by means of a pyramid system. The research team could be reached by email, telephone, and the messaging application WhatsApp.

At the time of interviewing (2015-2016), the interviewees were aged between 14 and 32 years. The foster care breakdowns they had experienced had occurred between 3 months and 16 years earlier. The placement with the shortest duration broke down after 3 years. The longest placement, experienced by a young woman, had lasted 16 years before breaking down.

Table 1 provides an overview of the sample $(N=12)$, the placement durations, the subjects' places of residence prior to the placement, and the solution adopted after the breakdown. All names are anonymized. 
International Journal of Child, Youth and Family Studies (2018) 9(1): 38-60

Table 1 Placement Durations with Living Situations Before and After Placement Breakdown

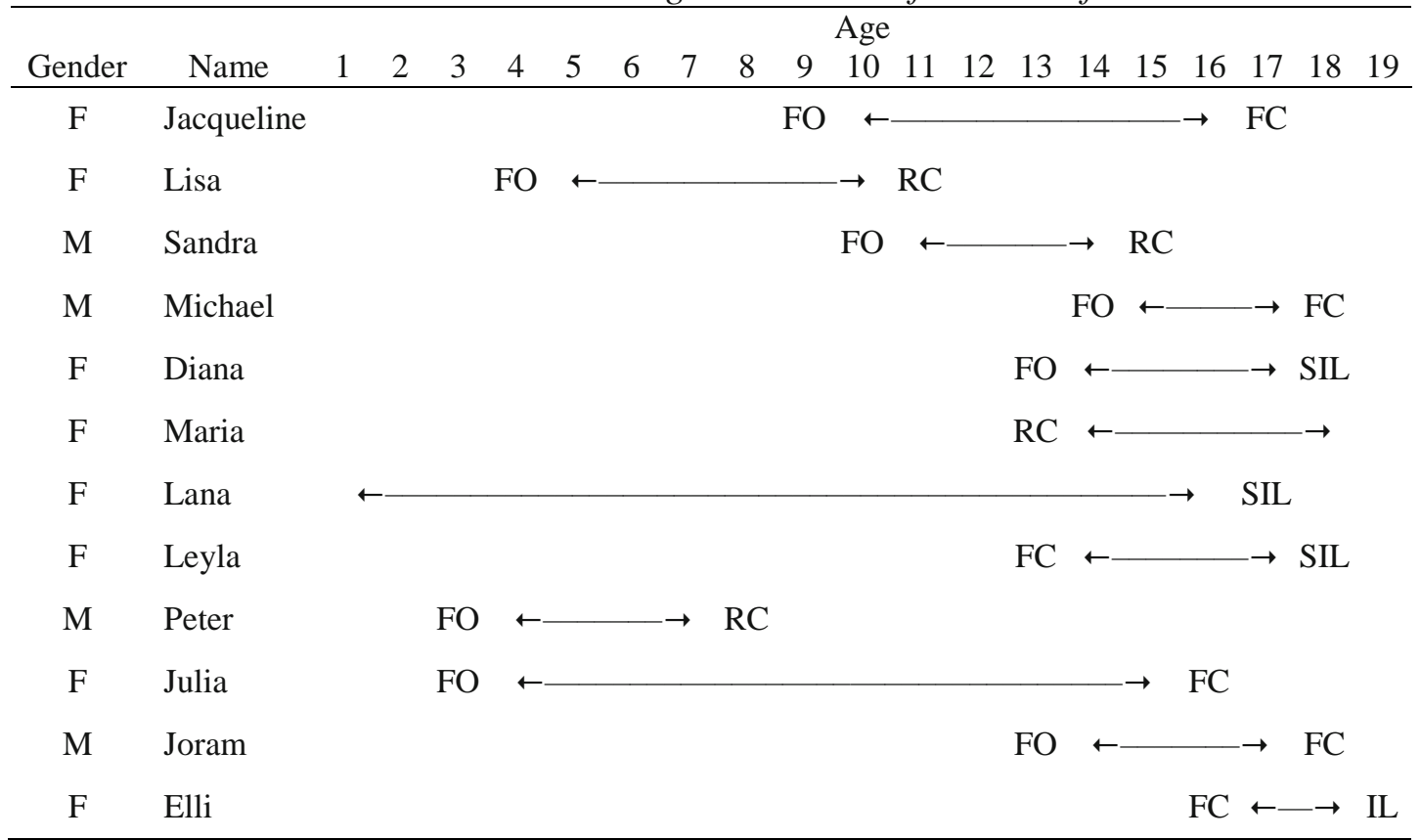

Note. $\mathrm{F}=$ female $\mathrm{M}=$ male; $\mathrm{FO}=$ family of origin; $\mathrm{RC}=$ residential care; $\mathrm{FC}=$ foster care; $(\mathrm{S}) \mathrm{IL}=($ supported $)$ independent living. The start and end of each arrow represent the ages at the start and end of each foster care placement.

\section{Interviews with Foster Children}

The semi-structured interviews were conducted at locations chosen by the young people and adults: for example, at the place of residence adopted as a solution after the breakdown (which might be a residential care home), the interviewees' private residence, outdoors by a river, in a café, or at the research institute. Contracts authorizing the anonymized use of the data in the context of the research project were signed at the beginning of the interview. The former foster children were asked to describe their lives before, during, and after the foster placement that had broken down. The audio recordings of the interviews were transcribed and anonymized and the information they contained was analyzed and evaluated using MAXQDA.

There was only one case in which both a foster child and the foster mother involved in the breakdown were available for interviewing. The reason for this was that the foster child had been re-placed with the foster family in which they had experienced the breakdown. Both parties agreed to each other being interviewed. For reasons of research ethics, none of the other cases involved the combining of perspectives on a single case. The interviews with the foster children involved different cases than the interviews in which foster parents were asked about their experiences, and their statements are not presented in this article.

\section{Processes Leading to Placement Change}

It emerged clearly from the accounts given in the interviews that foster care breakdowns are experienced as processes. Most interviews included the description of a period in which it was 
clear to the foster child that the placement was not proceeding in accordance with their wishes: they felt that they had not settled in the foster family, that they did not really belong there, or that they had problems expressing their needs. These sentiments are illustrated below based on the experiences of Jacqueline and Michael.

\section{“Happy Breakdown” and a Predictable End - Jacqueline's Experiences}

As a little girl, Jacqueline spent a few days a week on a day placement with a family. The time spent with the family was gradually increased and included overnight stays. When Jacqueline's mother was no longer able to take care of her, a permanent placement with a foster family was considered. Jacqueline was ten years old and no longer remembers the circumstances surrounding the placement or the reasons for the selection of her foster family. Conflicts quickly arose between Jacqueline and the foster mother and the other children in the foster family, and Jacqueline soon became aware that she did not want to stay with this foster family. She repeatedly reported this to her legal deputy ${ }^{4}$ over a period of years; however, the latter did not react. She then took the matter into her own hands and at the age of 16 finally moved to a new foster family, the family of a school friend, against the will of her foster mother.

\section{Stage of Life: A Better Option}

Jacqueline's case is exemplary for cases involving foster children who express their reservations and dissatisfaction with their foster families to third parties. The identity of these third parties varies from case to case: they can be family members, confidantes, deputies, or social workers. Although Jacqueline's request to her deputy initially fell on deaf ears, she repeatedly told both him and other people of her wish to leave the foster family. Jacqueline had a personal goal, something that provides important indications about her self-perception — in retrospect she was satisfied with her decision and thought it was right for her life — and had a sustained influence on her decision to leave the family.

The experiences reported in relation to the expression of reservations and dissatisfaction with foster care placements vary considerably and appear to depend on the foster child's network of contacts outside the foster family. Foster children who have a social network of trusted, approachable people use it to address difficult situations, and to seek out allies who agree with their decision to look for a placement change and who will support them in their interactions with decision-makers or persuade the latter to provide post-breakdown solutions.

\footnotetext{
${ }^{4}$ On the role and function of the Beistand [deputy] in the Swiss child and adult protection system, particularly in the foster care services: the deputy accepts a mandate "that can involve advice, consultation, representation and occasional checks and usually carries it out for a relatively long period of time" (Heck, 2015, p. 94). The tasks for which the deputy is responsible vary, depending on whether the placement is voluntary or was ordered by the child and adult protection authority; the professional background of deputies can also differ according to the background of the placement. The deputy is responsible for ensuring the well-being of the child, and maintains personal contact with the child, obtains an overview of the situation, advises, mediates, keeps written records, and interacts with other professionals who are involved in the supervision of the foster care placement (Heck, 2015, p. 94).
} 
International Journal of Child, Youth and Family Studies (2018) 9(1): 38-60

There are other foster children who, like Jacqueline, are capable of acting independently within their own situation. They activate networks, demand their rights and freedoms, and - even when their requests to their deputies are ignored - are capable of finding alternative solutions themselves and often participate in carrying them out. Of course, the fact that the ability to adopt such an active role is age-dependent applies to the young people in the sample under discussion here.

Foster children who make the decision on a relatively independent basis that they do not want to continue living in the foster family, and who have access to adults as allies in their social networks, are in a position to process the experience of a foster care breakdown as a "stage" in the course of their lives. For example, one young woman described such an experience as a "stage of life". Leyla reported, "I have the feeling that it's good how it turned out." Although she misses some aspects of the foster care situation, she can also see how it was better for her to leave the family. These foster children experience the breakdown process as comparatively positive in retrospect because they played an active part in assigning meaning to it. In such cases, breakdowns tend to be experienced as self-initiated and planned transitions that can be prepared for, followed up, and supervised as long as the support network (deputies, etc.) reacts promptly to the young person's needs, acknowledges the solutions they propose, and initiates the next steps to be taken. Relationships with the children, young people, and adults in former foster families that disband in this way are not necessarily terminated when the foster child moves out. On the contrary, they often continue, or at least are not terminated against the will of the former foster child. The dominant impression emerging from cases like Leyla's was, "I did this for myself and wanted it that way" - even if the retrospective assessment was not necessarily entirely positive and could also include experiences that reinforced sentiments such as, "If I don't do it, then nobody will care about me". Whatever the outcome, the experience of empowerment remained.

\section{Self-image and Future Expectations}

The retrospective assessment of these breakdowns was linked with the young person's view of themselves and with their expectations of the future. Accordingly, it was possible to establish that young people who had a positive self-image and could designate goals for their own lives were able to actively bring about breakdowns by independently seeking post-breakdown solutions or suggesting them to the decision-makers. Such breakdown processes were more rarely perceived as negative in retrospect and were seen instead as providing evidence of the feasibility of individual goal-setting.

\section{Escalation and a "Hard Cut"_-Michael's Experiences}

As also demonstrated by Unrau and Day (2010) and Unrau et al. (2008), there are foster children who associate foster care breakdown with experiences involving a loss of self-esteem, a loss of a sense of self-determination in relation to their own future, and a loss of friends and personal belongings. Examples presented by Unrau et al. (2008) show that such young people describe the breakdown process as a "time of shutting down" and an experience that stays with 
International Journal of Child, Youth and Family Studies (2018) 9(1): 38-60

them into adulthood (p. 1261). The Swiss sample included young people who described the breakdown of their foster care placement as unexpected, despite referring in the interview to situations and feelings that indicated that they did not feel comfortable in the family, that there were conflicts, or that they were actively working towards bringing the foster care relationship to an end. Michael's experience of foster care breakdown is an example of such a situation.

Michael was placed in a foster family with his brother. Prior to the placement, they lived with their mother and their two sisters. The search for foster parents who would take 15-year-old Michael and his 13-year-old brother proved difficult. However, Michael had one clear condition: he would only consider living in a foster family if he could stay with his younger brother. A foster family was found and Michael described the foster parents, who had adult children of their own, as friendly and helpful, somewhat strict, and expecting the foster children to organize their lives as independently as possible. Michael and his brother enjoyed this freedom but felt uneasy at the same time. When Michael stole from the foster parents, forged their signatures, and lied to them, they confronted him at the door of their house and would not let him back in. Following a meeting with the responsible authority, which Michael did not attend, he was placed in residential care. After some initial difficulties, Michael now has regular contact with his former foster parents again and with his younger brother who still lives with them.

\section{Point of No Return}

When a situation escalates and, as in Michael's case, a "point of no return" is reached whereby it is obvious that the foster child must leave the foster family, it is often evident that many questions remain open for the foster child and that the termination of the foster care placement will involve an abrupt loss of contact, which in many cases also applies to the child's siblings who remain with the foster family. This is associated with experiences characterized by a sense of powerlessness, a lack of agency, a lack of freedom, and very restricted rights of participation on the part of the child. Based on this, some experiences of foster care breakdown can be described as "hard cuts". Such situations are characterized by the fact that no plans have been made for the child's future prospects at the time of the breakdown. Michael's transition to the residential care home took place from one day to the next. He was not involved in the decision-making. He described in the interview how he lay crying on his bed in the care home, talking to his brother on the telephone. Another interviewee, Joram, was also informed about his deputy's decision at a meeting and was allowed no say. Because Joram had been breaking into houses and dealing drugs, he was informed that the only alternative for him was to go to a psychiatric facility. In the interview, Joram described himself at the time as a young man "who only ever screws things up". It was ultimately decided not to opt for the placement in a psychiatric facility and a time-out placement with a married couple was arranged for Joram. He was not very happy with this solution, however, and wished that he could return to the former foster family and live there again. His biological siblings remained with the family. He was not sure whether he would still be welcome there and was trying to arrange an appointment to discuss this with his deputy. 
International Journal of Child, Youth and Family Studies (2018) 9(1): 38-60

It emerged from the interviews that breakdowns that can be described as points of no return are often experienced as fast, hard cuts, which can also result in the termination of relationships with people in the foster family, including any biological siblings who remain there. The selfimage of the young people who have experienced this kind of breakdown tends to be uncertain and their sense of powerlessness is evident. Often, many questions remain unanswered. There are some former foster children who are unable to come to terms with such experiences of foster care breakdown, even many years later, and who remain uncertain about what exactly happened. Maria, for example, was informed by her foster parents one morning before going to school that "You must not come home here this evening." Her letter of apology went unanswered and she was blocked by the foster parents on the messaging application WhatsApp. Maria drew the following conclusion from this subjective experience:

"It's a breakdown. Because it's, I found it terrible. They never said to me before that I had to leave. But they did it because I am 18 and I find that really mean.

Because if you're sleeping on the street at 18 , then you're out of luck."

\section{Making Oneself Heard}

There are various indications that foster children whose deputies persistently ignore their wish to terminate a foster placement and who can find no alternative solutions adopt strategies that enable them to attain their objective themselves. Whereas those who have access to people who will actively represent their interests are able to act forcefully within their networks, young people in the aforementioned examples also act forcefully and independently to bring about the changes they want even without such support - albeit merely temporarily in many cases. Several of the interviewed foster children reported that despite repeated attempts to inform their deputies that they did not feel happy in their foster families, their pleas were ignored and they were fobbed off ("We'll reconsider it next year if you still feel the same; we'll see"), admonished ("That's life, it doesn't always go the way you want it to"), and even disparaged ("You're only going to end up on the streets anyway"). This prompts young men, in particular, to actively demand the attention of the professionals by, as Peter describes it, "acting particularly stupidly", and provoking reactions by actively disobeying rules, stealing, and so on. Decision-makers generally respond to this behaviour swiftly and punitively.

As our empirical material also shows, the foster care system responds very efficiently to behavioural problems. It is also evident to us that visible coping strategies (unlike invisible ones) succeed in prompting the professionals to react. However, in some cases they react too late, and with a hard cut, because the initial signs of a breakdown process have gone unacknowledged.

\section{Chaos: Nobody Knows What's Going On}

It emerges clearly from Peter's description that the experience of breakdown cannot be reduced to a particular point in time or action. He described himself as being in a chaotic situation that left him in the dark: 
International Journal of Child, Youth and Family Studies (2018) 9(1): 38-60

Because there was just always chaos and turmoil and because nobody really knew what exactly was going on. So I did not know what was happening then and ... I did not necessarily know about the re-placement either, what was going on there, and I don't think my two parents knew what was happening either and they did not ... complete chaos. ... The [deputies] knew everyone's opinions and were basically the central point that dispensed, did things and organized everything. I guess so, at least, I can’t really say.

It emerges here that Peter perceived himself as "uninformed" in contrast to the "informed" deputies, who from his point of view were not, however, in a position to impose order on the chaos. This statement is typical of the situation of many foster children who may know which actor has which rights and options in the process but do not experience them being put into practice. In the interviews, the former foster children were asked what advice they would give to a child or young person in a similar situation: all of the interviewees named the responsible adults in the process as people whom the child or young person should turn to immediately because — and the interviewees were aware of this - children and young people have the right to express their needs and certain people are responsible for ensuring these needs are met. It is interesting to note that this fictitious advice only matched the interviewees' own experiences of breakdown in very rare cases.

\section{Conclusion: The Importance of Interactive Biographical Contexts}

The cases outlined above clearly show that the designation of the process of foster care breakdown should not be divorced from the individual experience of it or understood in isolation from it. Rostill-Brookes et al. (2011) noted from their interviewing of young people that, 'Interestingly, terms like 'placement ending' or 'breakdown' did not filter into the young people's accounts; instead they referred to 'moving', 'leaving' and 'not being wanted"' (p. 111). The reported experiences clearly demonstrate that breakdowns are lived through in very different ways and, depending on the perspective, different dimensions become identifiable that cannot be related exclusively to a single point in time. Breakdowns are not isolated situations but processes, the start of which can be clearly identified by foster children. In order that foster care breakdown can be described as a process and understood as such, interactive and biographical contexts must be taken into account (Khoo \& Skoog, 2014). The understanding of the breakdown process "is dependent on perspectives and guided by interests" (Gehres, 2007, p. 84). To make the complexity of foster care breakdown understandable, different perceptions and experiences must be elucidated (van Santen, 2013). In other words, breakdown should be understood as a process that unfolds in stages: the situation of the child before the placement, the placing situation, and the manifestation of the crisis, as well as the actual breakdown event and the consequences for all actors involved.

Thus foster care breakdown involves processes that can only be explained by considering how they unfolded over time and by focusing on interactive factors at work on different levels that can both mitigate and reinforce each other. Hence we would recommend that the definition of 
foster care breakdown be closely linked with how it is experienced from an individual perspective. Breakdown occurs when it is perceived (retrospectively) as such. Assessments of such processes as planned, unplanned, expected, unexpected, formally ended but continuing on an informal basis, wanted, unwanted. and so on are made from the perspective of the actor involved (child or young person, foster parent, professional, etc.). This perspective must be clearly stated, and it must be acknowledged that different people experience and remember the same breakdown process individually and attribute different meanings to it and that these can change over time based on biographical perspectives. Once this complexity is acknowledged, the previously rather one-sided data pool consisting of quantitative file surveys can be supplemented and the results of such studies can be reinterpreted. Statements emerging from various interviews to the effect that children and young people must resort to conspicuous, loud, and difficult behaviour to get the attention of the support system shed new light on the finding that the behavioural problems of foster children are a cause of foster care breakdown. Thus it is necessary to carry out research that is oriented towards the subject of the research and that follows the socio-pedagogical premise of concentrating on the problems that young people actually have and not those that they create. 
International Journal of Child, Youth and Family Studies (2018) 9(1): 38-60

\section{References}

Bildungsdirektion Kanton Zürich. Amt für Jugend und Berufsberatung (2014). Stationäre Betreuung in Kinder-, Schul- und Jugendheimen. Richtlinien über Indikation, Voraussetzungen und Rahmenbedingungen für A. Timeout B. Umplatzierung C. Ausschluss [Inpatient care in children, school, and youth homes. Guidelines on indications, requirements and framework conditions for: A. Timeout, B. Replacement, C. Expulsion] (Bills/Resolutions). Zurich, Switzerland: Author.

Andersen, S. H. (2014). Complex patterns: On the characteristics of children who experience high and low degrees of foster-care drift. British Journal of Social Work, 44, 1545-1562. doi:10.1093/bjsw/bcs178

Backe-Hansen, E. (2010). How to counteract and prevent foster home breakdown? In E. J. Knorth, M. E. Kalverboer \& J. Knot-Dickscheit (Eds.), Inside out: How interventions in child and family care work. an international source book (pp. 239-240). Antwerp, Apeldoorn: Garant Publishers.

Barber, J. G., \& Delfabbro, P. H. (2003). Placement stability and the psychosocial well-being of children in foster care. Research on Social Work Practice, 13, 415-431. doi: $10.1177 / 1049731503013004001$

Bericht und Antrag des Regierungsrates. (2007). An den Kantonsrat zum Postulat KR-Nr.55/2003 betreffend bessere Arbeitsbedingungen für Pflegefamilien, 4376 KR-Nr. 55/2003 [To the cantonal council on the postulate KR-55/2003 regarding better working conditions for foster families, $4376 \mathrm{KR}-55 / 2003]$.

Berridge, D., \& Cleaver, H. (1987). Foster home breakdown. Oxford, UK: Basil Blackwell.

Blandow, J. (2004). Anders als die anderen ... die Grosseltern- und Verwandtenpflege [Different from the others ... Grandparent and relative care] (Unpublished manuscript). Retrieved from

https://www.dji.de/fileadmin/user_upload/pkh/HB2011/DJI_DIJUF_Pflegekinderhilfe_C12. pdf

Bombach, C., Stohler, R., \& Wydler, H. (2015). Farming families as foster families: The findings of an exploratory study on care farming in Switzerland. International Journal of Child, Youth \& Family Studies, 6(3), 440-457. doi:10.18357/ijcyfs.63201513564

Brown, J. D., Bednar, L. M., \& Sigvaldason, N. (2007). Causes of placement breakdown for foster children affected by alcohol. Children and Adolescent Social Work Journal, 24(4), 313-332. doi:10.1007/s10560-007-0086-9 
International Journal of Child, Youth and Family Studies (2018) 9(1): 38-60

Christiansen, Ø., Havik, T., \& Anderssen, N. (2010). Arranging stability for children in longterm out-of-home care. Children and Youth Services Review, (32), 913-921. doi:10.1016/j.childyouth.2010.03.002

Delap, E., \& Melville Fulford, L. (2011). Fostering better care: Improving foster care provisions around the world (Positive care choices: Working paper 2). London, UK: EveryChild. Retrieved from https://bettercarenetwork.org/sites/default/files/Fostering Better Care Improving Foster Care Provision Around the World.pdf

Egelund, T., \& Vitus, K. (2009). Breakdown of care: The case of Danish teenage placements. International Journal of Social Welfare, (18), 45-56. doi:10.1111/j.1468$\underline{2397.2008 .00564 . x}$

Ekins, A. (2009). Placement stability. PART: Practice and Research Together. Retrived from http://www.partcanada.org/member-login?denied=ptype_line_234_no_front_user

Festinger, T. (2014). Adoption disruption. In G. P. Mallon \& P. McCartt Hess (Eds.), Child welfare for the twenty-first century: A handbook of practices, policies, and programs (2nd ed., pp. 438-454). New York, NY: Columbia University Press.

Gabriel, T., \& Stohler, R. (2008). Switzerland. In M. Stein \& E. R. Munro (Eds.), Young people's transitions from care to adulthood: International research and practice. (pp. 197208). London, UK: Philadelphia.

Geertz, C. (1987). Dichte Beschreibung. Beiträge zum verstehen kultureller Systeme [Thick description. Towards an interpretative theory of culture]. Frankfurt, Germany: Suhrkamp.

Gehres, W. (2007). "Scheitern” von Pflegeverhältnissen - ein Klärungsversuch zur Sozialisation in Pflegefamilien ["Failure" of foster care relationships: An attempt to clarify the socialisation of foster families]. Zeitschrift Für Soziologie Der Erziehung Und Sozialisation, 27(1), 73-87.

Gilbertson, R., \& Barber, J. G. (2003). Breakdown of foster care placement: Carer perspectives and system factors. Australian Social Work, 56(4), 329-339. doi:10.1111/j.1447$\underline{0748.2003 .00095 . x}$

Heck, C. (2015). Überblick über die Akteure und deren Aufgaben [Overview of the actors and their tasks]. In D. Rosch, C. Fountoulakis, \& C. Heck (Eds.), Handbuch Kindes- und Erwachsenenschutz. Recht und Methodik für Fachleute (pp. 89-97). Bern, Switzerland: Haupt. 
International Journal of Child, Youth and Family Studies (2018) 9(1): 38-60

Hédervári-Heller, É. (2000). Eine Untersuchung zu "vorzeitigen/ungeplanten Beendigungen von Pflegeverhältnissen (Abbrüche) nach § 33 SGB VIII im Land Brandenburg im Jahr 1997", (Gutachten) [An investigation into "premature/unplanned terminations of care relationships (interruptions) according to $§ 33$ SGB VIII in the state of Brandenburg in 1997" (Report)]. Oranienburg, Germany: Landesjugendamt im Land Brandenburg.

Heinemann, C. (1994). Neuentscheidungstherapie bei Pflege-, Adoptiv- und Heimkindern mit Scheiterer-verläufen [New decision therapy for foster, adoptive and home children with failures]. Praxis Der Kinderpsychologie Und Kinderpsychiatrie, 43(4), 130-137.

Hyde, J., \& Kammerer, N. (2009). Adolescents' perspectives on placement moves and congregate settings: Complex and cumulative instabilities in out-of-home care. Children and Youth Services Review, 31(2), 265-273. doi:10.1016/j.childyouth.2008.07.019

Jackson, S., \& Cameron, C. (2012). Leaving care: Looking ahead and aiming higher. Children and Youth Services Review, 34, 1107-1114. doi:10.1016/j.childyouth.2012.01.041

James, S. (2004). Why do foster care placements disrupt? An investigation of reasons for placement change in foster care. The Social Service Review, 78(4), 601-627. doi: $10.1086 / 424546$

Kalland, M., \& Sinkkonen, J. (2001). Finnish children in foster care: Evaluating the breakdown of long-term placements. Child Welfare League of America, 80(5), 513-527.

Kantonales Jugendamt. (2016). Projekt ”Optimierung der ergänzenden Hilfen zur Erziehung im Kanton Bern" [Project "Optimisation of supplementary aids for education in the Canton of Berne"] (Datenbericht 2015, version 0.1). Bern, Switzerland: Author.

Keller, A. (2012). Familienplatzierungs-Organisationen in der Schweiz. Bericht zuhanden der Konferenz der kantonalen Sozialdirektorinnen und Sozialdirektoren [Family placement organisations in Switzerland. Report to the Conference of Cantonal Social Directors], BrigGlis, Switzerland. Zurich, Switzerland: Fachstelle Integras.

Khoo, E., \& Skoog, V. (2014). The road to placement breakdown: Foster parents' experiences of the events surrounding the unexpected ending of a child's placement in their care. Qualitative Social Work, 13(2), 255-269. doi:10.1177/1473325012474017

Kindler, H., Helmig, E., Meysen, T., \& Jurczyk, K. (Eds.). (2011). Handbuch Pflegekinderhilfe [Manual: Foster Care]. Munich, Germany: Deutsches Jugendinstitut. 
International Journal of Child, Youth and Family Studies (2018) 9(1): 38-60

Kuntsche, E. N., \& Nett, J. C. (2002). Zur Situation der stationären Erziehungseinrichtungen in der Schweiz. Eine Bedarfsanalyse wissenschaftlicher Begleitforschung [On the situation of inpatient educational institutions in Switzerland. A needs analysis of accompanying scientific research]. Vierteljahresschrift Für Heilpädagogik Und Ihre Nachbargebiete VHN $71,426-439$.

López López, M., del Valle, J. F., Montserrat, C., \& Bravo, A. (2011). Factors affecting foster care breakdown in Spain. The Spanish Journal of Psychology, 14(1), 111-122. doi:10.5209/rev_SJOP.2011.v14.n1.9

Newton, R. R., Litrownik, A. J., \& Landsverk, J. A. (2000). Children and youth in foster care: Disentangling the relationship between problem behaviors and number of placements. Child Abuse \& Neglect, 24(10), 1363-1374. doi:10.1016/S0145-2134(00)00189-7

Nienstedt, M., \& Westermann, A. (1999). Die Chancen von Kindern in Ersatzfamilien [The chances of children in surrogate families]. In H. Colla, T. Gabriel, S. Millham, S. MüllerTeusler, \& M. Winkler (Eds.), Handbuch Heimerziehung und Pflegekinderhilfe in Europa (pp. 791-800). Neuwied, Kriftel, Germany: Luchterhand.

Oosterman, M., Schuengel, C., Slot, N. W., Bullens, R. A. R., \& Doreleijers, T. A. H. (2007). Disruptions in foster care: A review and meta-analysis. Children and Youth Services Review 29, 53-76. doi:10.1016/j.childyouth.2006.07.003

Palmer, S. E. (1990). Group treatment of foster children to reduce separation conflicts associated with placement breakdown. Child Welfare League of America, 69(3), 227-238.

Pecora, P. J. (2010). Why should child welfare focus on promoting placement stability? In T. LaLiberte \& P. J. Pecora (Eds.), CW360 : A comprehensive look at a prevalent child welfare issue, Spring, 4-5. St. Paul, MN: School of Social Work, College of Education and Human Development, University of Minnesota.

Pecora, P. J., Kessler, R. C., Williams, J., O’Brien, K., Downs, C. A., English, D., ... Holmes, K. (2005). Improving family foster care: Findings from the Northwest Foster Care Alumni study (The Foster Care Alumni Studies: Stories from the past to shape the future). Seattle, WA: Casey Family Programs.

Pecora, P. J., Williams, J., Kessler, R. C., Downs, C. A., O’Brien, K., Hiripi, E., \& Morello, S. (2003). Assessing the effects of foster care: Early results from the Casey National Alumni study. (The Foster Care Alumni Studies: Stories from the past to shape the future). Seattle, WA: Casey Research Services.

Price, J. M., Chamberlain, P., Landsverk, J., Reid, J. B., Leve, L. D., \& Laurent, H. (2008). Effects of a foster parent training intervention on placement changes of children in foster care. Children Maltreatment, 13(1), 64-75. doi:10.1177/1077559507310612 
International Journal of Child, Youth and Family Studies (2018) 9(1): 38-60

Proch, K., \& Taber, M. A. (1985). Placement disruption: A review of research. Children and Youth Services Review, 7, 309-320. doi:10.1016/S0190-7409(85)80004-9

Reimer, D. (2015). Übergänge als Kulturwechsel und kritische Lebensereignisse [Transitions as cultural change and critical life events]. In K. Wolf (Ed.), Sozialpädagogische Pflegekinderforschung (pp. 61-84). Bad Heilbrunn, Germany: Julius Klinkhardt.

Rock, S., Michelson, D., Thomson, S., \& Day, C. (2013). Understanding foster placement instability for looked after children: A systematic review and narrative synthesis of quantitative and qualitative evidence. British Journal of Social Work, 45(1), 177-203. doi:10.1093/bjsw/bct084

Rostill-Brookes, H., Larkin, M., Toms, A., \& Churchman, C. (2011). A shared experience of fragmentation: Making sense of foster placement breakdown. Clinical Child Psychology and Psychiatry, 16(1), 103-127. doi:10.1177/1359104509352894

Rubin, D. M., O’Reilly, A. L. R., Luan, X., \& Localio, A. R. (2007). The impact of placement stability on behavioral well-being for children in foster care. Pediatrics, 119(2), 336-344. doi:10.1542/peds.2006-1995

Sallnäs, M., Vinnerljung, B., \& Kyhle Westermark, P. (2004). Breakdown of teenage placements in Swedish foster and residential care. Child and Family Social Work, 9, 141-152. doi:10.1111/j.1365-2206.2004.00309.x

Semanchin Jones, A., \& Wells, S. J. (2008). PATH/Wisconsin - Bremer project: Preventing placement disruptions in foster care (Final report). St. Paul, MN: Regents of the University of Minnesota.

Stein, M. (2006). Research review: Young people leaving care. Child and Family Social Work, 11, 273-279. doi:10.1111/j.1365-2206.2006.00439.x

Stein, M. (2012). Young people leaving care. London, UK: Jessica Kingsley.

Unrau, Y., \& Day, A. (2010). The importance of understanding the placement move experience from the perspective of foster youth. In T. LaLiberte \& P. J. Pecora (Eds.), $C W 360^{\circ}: A$ comprehensive look at a prevalant child welfare issue, Spring, 11. St. Paul, MN: School of Social Work, College of Education and Human Development, University of Minnesota.

Unrau, Y. A. (2007). Research on placement moves: Seeking the perspective of foster children. Children and Youth Services Review, 29(1), 122-137. doi:10.1016/j.childyouth.2006.08.003

Unrau, Y. A., Seita, J. R., \& Putney, K. S. (2008). Former foster youth remember multiple placement moves: A journey of loss and hope. Children and Youth Services Review, 30(11), 1256-1266. doi:10.1016/j.childyouth.2008.03.010 
International Journal of Child, Youth and Family Studies (2018) 9(1): 38-60

van Santen, E. (2013). Factors associated with placement breakdown initiated by foster parents: Empirical findings from Germany. Child \& Family Social Work, 20, (2), 191-201. doi:10.1111/cfs. 12068

Vanderfaeillie, J., Van Holen, F., \& Coussens, S. (2008). Why do foster care placements break down? A study on factors influencing foster care placement breakdown in Flanders.

International Journal of Child \& Family Welfare, 2(3), 77-87.

Vinnerljung, B., Sallnäs, M., \& Berlin, M. (2014). Placement breakdowns in long-term foster care: A regional Swedish study. Child \& Family Social Work, 22(1), 15-25. doi:10.1111/cfs.12189

Ward, H. (2009). Patterns of instability: Moves within the care system, their reasons, contexts and consequences. Children and Youth Services Review, 31(10), 1113-1118. doi:10.1016/j.childyouth.2009.07.009

Wilson, K., Sinclair, I., \& Gibbs, I. (2000). The trouble with foster care: The impact of stressful events on foster carers. British Journal of Social Work, 30(2), 193-209. doi:10.1093/bjsw/30.2.193

Wulczyn, F. (2010). Placement stability in the context of federal policy. In T. LaLiberte \& P. J. Pecora (Eds.), $C W 360^{\circ}$ : A comprehensive look at a prevalant child welfare issue, Spring, 67. St. Paul, MN: School of Social Work, College of Education and Human Development, University of Minnesota.

Zatti, K. B. (2005). Das Pflegekinderwesen in der Schweiz. Analyse, Qualitätsentwicklung und Professionalisierung [The foster child care system in Switzerland. Analysis, quality development and professionalization] (Expert report). Bern, Switzerland: Federal Office of Justice. 